\title{
Mean operating room times differ by $50 \%$ among hospitals in different countries for laparoscopic cholecystectomy and lung lobectomy
}

\author{
Franklin Dexter $^{1}$, Melinda Davis ${ }^{2}$, Christoph B. Egger Halbeis ${ }^{3}$, Ritta MarjamaA ${ }^{4}$ Jean Marty $^{5}$, \\ Catherine McIntosh ${ }^{6}$, Yoshinori Nakata ${ }^{7}$, Kokila N. Thenuwara $^{8}$, Tomohiro Sawa ${ }^{9}$, and Michael Vigoda ${ }^{10}$ \\ ${ }^{1}$ Director of the Division of Management Consulting, Professor, Departments of Anesthesia and Health Management and Policy, \\ University of Iowa City, Iowa, USA \\ ${ }^{2}$ Staff Anesthesiologist, Foothills Medical Centre, University of Calgary Faculty of Medicine, Calgary, Alberta, Canada \\ ${ }^{3}$ Clinical Instructor, Department of Anesthesia \& ICU, Kantonsspital Liestal, Affiliated Hospital of the University of Basel Medical School, \\ Liestal, Switzerland; Clinical Instructor, Department of Anesthesia, Stanford University School of Medicine, Stanford, California, USA \\ ${ }^{4}$ Staff Anesthesiologist, Department of Anesthesia and Intensive Care Medicine, Helsinki University Central Hospital, Helsinki, Finland \\ ${ }^{5}$ Professor and Chairman, Service d'anesthésie-réanimation, Hopital Henri Mondor, Creteil, France \\ ${ }^{6}$ Postdoctoral Fellow, Department of Anesthesia, Stanford University School of Medicine, Stanford, California, USA; Staff Specialist in \\ Anaesthesia, John Hunter Hospital, Hunter New England Health Service, Newcastle, New South Wales, Australia \\ ${ }^{7}$ Professor and Chairman, Teikyo University School of Medicine, Ichihara Hospital, Ichihara, Chiba, Japan \\ ${ }^{8}$ Consultant Anesthesiologist, Asiri Hospitals, Colombo 5, Sri Lanka; Visiting Assistant Professor, Department of Anesthesiology, University \\ of Iowa, Iowa, USA \\ ${ }^{9}$ Associate Professor, Chief Information Officer, Teikyo University School of Medicine, Ichihara Hospital, Chiba, Japan \\ ${ }^{10}$ Director of the Center for Informatics and Perioperative Management, Department of Anesthesiology, University of Miami, Jackson \\ Memorial Hospital, Miami, Florida, USA
}

Erratum to:

J Anesth (2006) 20:319-322

DOI 10.1007/s00540-006-0419-4

The correct name of the third author should be given as Christoph B. Egger Halbeis, not Christoph E. Halbeis.

Accordingly, the contents should read:

\author{
Mean operating room times differ by $50 \%$ among \\ hospitals in different countries for laparoscopic \\ cholecystectomy and lung lobectomy \\ F. Dexter, M. Davis, C.B. Egger Halbeis, \\ R. Marjamaa, J. Marty, C. McIntosh, Y. Nakata, \\ K.N. Thenuwara, T. Sawa, M. Vigoda 319
}

The online version of the original article can be found at http://dx.doi.org/10.1007/s00540-006-0419-4 